\title{
Organization, Not Inspiration: A Historical Perspective of Musical Information Architecture
}

\author{
Graham Freeman*, Robert J. Glushko** \\ *Dan School of Drama and Music, Queen's University, Harrison LeCaine Hall, 39 Bader Lane, \\ Kingston, Ontario, Canada, K7L 3N6, <dr.graham.freeman@protonmail.com> \\ ** University of California, Berkeley, Cognitive Science Program, 140 Stephens Hall, \\ Berkeley CA 94720, USA, <glushko@berkeley.edu>
}

\begin{abstract}
Graham Freeman is a musicologist and technical writer in Toronto, Canada. He received his PhD from the University of Toronto and is currently teaching at Queen's University and at George Brown College.

Bob Glushko is an adjunct full professor at the University of California at Berkeley in the Cognitive Science Program. He has had more than thirty years of experience in information systems and service design, content management, electronic publishing and ebooks, internet commerce, and human factors in computing systems. He founded or co-founded four companies, including Veo Systems in 1997, which pioneered the use of XML for electronic business. Veo's innovations included the Common Business Library (CBL), the first native XML vocabulary for business-to-business transactions, and the Schema for Object-Oriented XML (SOX), the first object-oriented XML schema language.
\end{abstract}

Freeman, Graham and Robert J. Glushko. 2019. "Organization, not Inspiration: A Historical Perspective of Musical Information Architecture.” Knowledge Organization 46(3): 161-170. 28 references. DOI:10.5771/09437444-2019-3-161.

Abstract: The organization of musical resources in a piece of music is opaque for everyone but for those with the highest levels of musical education. For the average listener, the specific vocabulary of musical organization is usually replaced by metaphorical language relating to inspiration and musical affect, or by a social perspective that rids the music of its specific theoretical language and provides a more relatable perspective of the music as a historical and communal event. We examine the ways in which information architecture and organizational theory can surface the inner workings of music in a relatable and approachable way. We consider music as a series of design resources that composers draw upon and organize according to a series of constraints that create a sense of musical structure to which the listener can relate. After a general introduction to the literature relating to constraints and creativity, we use two historical anecdotes that provide accessible demonstrations of how

musicians in the seventeenth and twentieth centuries organized their musical resources both for their own compositional needs and for the purposes of didactic communication.

Received: 23 September 2018; Revised: 26 January 2019; Accepted: 27 March 2019
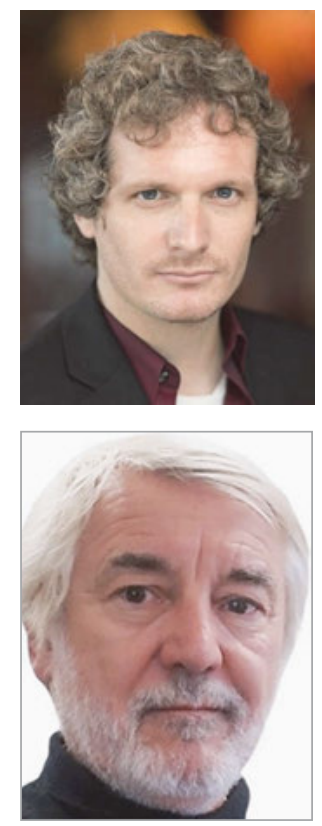

Keywords: music, musical resources, constraints, organizing systems, composers, information

\subsection{Introduction}

For those with no experience writing music, the process by which it happens is opaque, with the catalyst for it being something mysterious and difficult to define called "inspiration." Igor Stravinsky $(1998,50)$ referred to it as a "hazy emotive disturbance that sets the composer's creative imagination in motion." But how do we take that "emotive disturbance" and create music from it? Once inspiration arrives, we might ask any one of a number of very reasonable questions: "In what style should I compose?," "What tonal- ity?;” “What genre?;” "Which structure?” If we have no musical experience, we might ask even more fundamental questions like "Which notes should I use?;" "Should I use all the notes or just some of them?" or; "What should the duration of each note I play be?"

If we have every possible musical design resource at our disposal, it can be paralyzing even to imagine where to begin organizing them into music. This phenomenon is what psychologist Barry Schwartz calls (2004) the paradox of choice, in which an overwhelming number of alternatives creates information overload that prevents any meaningful interac- 
tion with the information or resources presented. Even Stravinsky can experience the anxiety this can produce (Stravinsky 1998, 63):

I experience a sort of terror when, at the moment of setting to work and finding myself before the infinitude of possibilities that present themselves, I have the feeling that everything is permissible to me. If everything is permissible to me, the best and the worst; if nothing offers me any resistance, then any effort is inconceivable, and I cannot use anything as a basis, and consequently every undertaking becomes futile.

To overcome this anxiety, a composer must impose constraints, and music is, therefore, rich in constraints that rein in the number of options. At a very high level, these constraints determine what arrangements of musical resources are considered stylistically acceptable within a specific genre or culture. More specifically, constraints are a way of organizing musical material and limiting choices to prevent cognitive overload and to help composers find a reasonable path forward through the seemingly infinite number of musical options. As Stravinsky described it (1998, 65):

My freedom thus consists in my moving about within the narrow frame that I have assigned myself for each one of my undertakings. I shall go even further: my freedom will be much the greater and more meaningful the more narrowly I limit my field of action and the more I surround myself with obstacles. Whatever diminishes constraint, diminishes strength. The more constraints one imposes, the more one frees one's self of the chains that shackle the spirit.

Form provides an excellent example of a musical constraint. For much of the history of western art music (WAM), composers have used recognizable structures for their music. Among these are sonata form, a large form divided into three or four separate movements that are often unified by key or thematic material, and dance forms, which were short musical structures having their historical origins in socially performed dances. The benefit of these forms is that their prescriptive structures provided composers with a path along which they could develop their musical material and make it relatively familiar to the listener, like a container into which the musical material can be poured.

The diversity of musical practice from different regions and eras demonstrates the various ways in which musicians have constrained musical material. We call these sets of constraints and the design decisions that embody them "organizing systems" (Glushko 2016), "an intentionally arranged collection of resources and the interactions they support." Some of these organizing systems, like western tonality or Hindustani practices, have very long histories of established practice, in which constraints have been carefully selected, developed, and pruned over many hundreds of years. Other practices, such as the music of the twentieth-century avant-garde, feature composers creating their own individual organizing systems, often using different constraints for every piece they compose.

Musical organizing systems have been the subject of several important studies in the field of knowledge organization over the last several years. Representative examples include Smiraglia, whose work (2002, 2017; Thomas and Smiraglia 1998; Smiraglia and Graf 2017) has been perhaps the most valuable contribution to the classification of printed and recorded musical materials. Adcock (2001) has examined the challenge of creating classification systems for printed and recorded music that increase the accessibility of musical artifacts for the visually impaired. Wu and Shi (2016) have met the challenge of exploring a classification system that provides precise categories and metadata for classical music recordings on the internet. Weissenberger's (2015) work on the classification of traditional music genres expands the concept of documented music to include alternative forms of knowledge such as oral/aural transmission of musical material. Abrahamsen (2003) has explored the role of ontology in the neglected classifications of popular music in musicology. Finally, Lee (2017a, 2017b, 2019) has explored the distinction between scientific and bibliographic classification and the challenges of classification systems for the various sub-categories of instrumental music ensembles.

To complement the existing literature on the challenges of classifying of musical artifacts, we will explore some historical examples of classifying the musical material itself. This article is about considering music as architecture, in which musical resources are assembled and constrained to create a structure in the form of a musical work. This perspective of musical architecture is not designed to replace traditional methods of music theory or analysis, but rather to demonstrate that musical thought has some very specific resonances with the architectural metaphor. In particular, we focus on the tools and materials of information architecture (IA). The purpose of showing the complementarity of these two disciplines is to demonstrate the ways in which musical thought resonates strongly with two fundamental principles of IA: 1) organizing resources for retrieval and use; and; 2) sensemaking, and that musicians are inherently excellent information architects of their own design resources. In addition, analyzing music as the result of systematic architectural thinking is easier and more useful than viewing it as the product of opaque inspiration.

After some brief background on the theory of constraints and IA, we will examine some different ways in 
which musicians have created musical architectures that resonate closely with IA. For the sake of brevity, we provide examples from WAM, but the agnostic nature of this approach will prove to be well-suited to musical architectures from any time or place. This approach has been developed during many years of teaching music history and theory to non-musicians enrolled in general music history courses in a university setting, with continual modifications and fine-tuning in response to the ongoing interactions with students and their input.

\subsection{Constraints and IA}

Why is IA the appropriate framework for this discussion? IA is strongly associated with website design, but Glushko provides $(2016,115)$ a better definition as "designing an abstract and effective organization of information and then exposing that organization to facilitate navigation and information use." According to Glushko, the process for creating the organizing system that sits at the foundation of IA is:

- Selecting the resources that will be organized

- Organizing the resources according to rules or constraints

- Designing interfaces to the resources to facilitate retrieval and use, and

- Maintaining and adapting the system over time.

IA provides the tools for the task of sensemaking in which people use the resources they have organized to interpret the world, survive their environments, be innovative with existing resources, and even invent new resources. Arango (2011) suggests that IA and traditional architecture share the common goal of intentionally designing environments to facilitate a specific goal. For traditional architecture, the goal is to create a habitable space; for IA, it is to help a user to navigate and put to use the overwhelming deluge of information that surrounds us.

Musicians facilitate understanding of their musical environments by thinking of composition as the application of hierarchical constraints that progressively organize the musical design material. The current literature on creativity and innovation is rich with excellent analyses of the way in which constraint-based thinking promotes creative problem solving. Stokes (2013) writes, for example, that there are four levels of constraints arranged in a hierarchy that descends from the breadth of genre and style to the granularity of materials and resources. Constraints are then either adhered to in order to maintain the expectations of style and genre or they are broken for the purpose of innovation and expanding into new creative areas. Building on Stokes' typology of constraints, Fishman (2015) pro- poses a model using generative constraints to show how the use of existing design resources at various levels of granularity created by other artists can be squared against copyright law.

Beyond the perspective that music is simply about applying basic constraints, cognitive science has been a vital tool in examining the complexity of musical understanding and the multiple organizational levels on which musical decisions are made by composers and perceived by listeners. Musical sounds have no defined semantic meaning. Instead, musical structure operates on multiple structural levels simultaneously, which requires the listener to extract complex information such as pitch, timbre, and duration. Pearce and Rohrmeier (2012) describe each element of musical information as involving multiple cognitive processes. Composers, therefore, operate with the understanding that every musical constraint they apply provokes in the listener, even one with only a passing familiarity with the musical genre they are hearing, a complex set of cognitive processes that anticipate the fulfillment of their tacit expectations regarding the organization of fundamental musical resources.

Finally, composers recognize that music is constrained by the medium of its transmission. For those in the WAM tradition, music is transmitted to other musicians typically through notation with the tacit understanding that the symbols on the page represent the prescriptive procedures for turning visual representations of sound into aural realizations. Western notation imposes its own constraints on what it is possible to document with visual symbols. Many composers have attempted to break free of these constraints with new notational systems that included extended symbols, written instructions, graphic representations of sound waves, and code-based notation. Contemporary musicians in popular or electronic genres will frequently use sound recordings of performances or rehearsals, face-to-face communication, or collaborative technology to transmit and document their organization of musical material, often to avoid the difficulties of fitting the piece into the constraints of traditional notation or of creating a bespoke notational representation.

Yet what do we do with these insights, and what does a better understanding of artistic creativity and musical perception provide for us as listeners, observers, or participants in that activity? By augmenting our musical perspective with tools derived from IA, we can provide additional domain-agnostic insights that enhance the way we talk about music and the lessons we can extract from it. To do this, we need to tell two stories about how music resonates with the principles of IA. The first, about the music of Arnold Schoenberg, shows how resource selection and organization can lead to innovative new developments of musical praxis. The second, about the theoretical work of Jean-Philippe Rameau, shows how resource selection and 
organization can facilitate revolutionary new approaches to musical sensemaking. Our observations here remain within the scope of notation-based representations of music, but this approach is applicable to musical transmission in any representational media.

\subsection{General introduction to musical constraints}

Charting a quick and accessible history of musical organizing systems in WAM is not an easy task. While it would be convenient to have a tidy narrative in which musical developments build upon one another and cascade along an efficient path like a sort of waterfall methodology, the truth is considerably messier and replete with many innovative, iconoclastic, nonlinear and sometimes even regressive developments. Nevertheless, it will prove helpful for our purposes to include a short guide to harmony in WAM since the eighteenth-century, one that provides enough of a summary to demonstrate the value of the IA perspective on the history of theory while also providing a few tantalizing hints for future work.

The best place to begin is with the concept of tonality. Tonality has been a dominant framework for organizing musical materials since the eighteenth-century, and it continues that dominance in contemporary popular music. This makes tonality the primary concept that people use to understand western musical harmony, whether they know anything about music theory or not.

Tonality is an organizing system that governs the progression of musical events in a piece of music. Many theorists have proposed that the way the rules of tonality govern musical events is similar to the way the rules of grammar govern linguistic communication, with melodies, chords and other musical materials replacing those of language such as verbs and nouns.

The eighteenth- and early nineteenth-centuries constitute what is often referred to as the "common practice period," which denotes a period in which general best practices regarding tonality prevailed throughout Europe and dictated stylistically acceptable compositional practice. This approach to tonality also defined the parameters against which innovators would push to establish new means of musical expression and organization. Mozart, Beethoven and Haydn, to name just a few examples, are late eighteenth- early nineteenth-century composers with diverse compositional outputs for whom tonality constituted the common fundamental language of their time.

Perhaps the most significant constraint within the tonal system is that concerning the relationship of consonance and dissonance. The definitions of these terms are difficult to pin down. Indeed, Tenney has written $(1988,1)$ that "There is nothing in the language of discourse about music that is more burdened with purely semantic problems than are the terms consonance and dissonance." This is largely the result of a constantly shifting definition of what constitutes a dissonance, as we shall see below. A useful basic definition of consonance is a combination of tones that sound settled, as though they are pleasant enough that they do not unto themselves suggest the need to move any further to be nice to listen to. Dissonance, in contrast, is created by a combination of tones that sound harsh or unsettled, as though they are imbued with a tension that requires their continued movement to consonant combinations to find resolution. Consonance and dissonance are, therefore, organizing principles with a defined semantic relationship between them, one that the composer can manipulate to create and extend musical interest. Dissonance produces the expectation of resolution to consonance, and composers will use that either to provide or deny the listener the fulfillment of those expectations. According to Salimpoor et al. (2015), the use of dissonance to create the sense of expectation in the listener is part of the composer's powerful ability to strategically manipulate the listener's response. The constraints that govern the balance between consonance and dissonance form the basis of tonality, which is the fundamental grammar of music during the common practice period.

Consonance and dissonance are not absolute concepts, and they are in no way universal. Over time, as well as across geographies, the concepts of what sounds are consonant or dissonant can vary considerably, even today. It is the relationship between them, and how one progresses from one to the other, that constitutes the constraint. $\mathrm{Mu}$ sic that is entirely consonant might be immediately sonorous for the ears, but the listener would quickly tire of the lack of tension, contrast, and interest in the musical materials. Dissonance is, therefore, a necessary and vital part of musical organization, and it is how this relationship is managed that has changed so significantly over time.

In the eighteenth-century of Mozart, dissonance was a principle that was carefully governed by the strict constraints of tonality. Like the physical element of fire, it was the vital catalyst for creating energy, but also one that could destroy the entire architecture if left unchecked. Eighteenth-century tonality, therefore, constrained dissonance to a transitional stage between moments of consonance. Dissonant musical notes were to be preceded by consonant ones and should release the tension they created by subsequently resolving into consonance. Composers could, of course, strain against those constraints for the purposes of artistic expression. Mozart's String Quartet K. 465 , aptly nicknamed "Dissonance," is an excellent example of a work that briefly moves to the very edge of the tonal constraint on dissonance to produce a riveting and dramatic musical effect, all the while remaining within the parameters of the constraint. Mozart achieves this effect 
with an extended introduction that emphasizes dissonance and a lack of harmonic direction that eventually moves to the home key in a cathartic resolution.

One of the defining characteristics of music in the nineteenth-century is the increasingly liberal way in which composers treated the constraint on dissonance. By the end of his life, Beethoven had begun to infuse his music with a decidedly more expressive treatment of dissonance, though still within the bounds of the tonal constraints, as one can hear by comparing, for example, the early String Quartet No. 1 op. 18 in F Major to the much later op. 133 ("Große Fuge”). Later composers such as Richard Wagner, Claude Debussy and Alexander Scriabin found innovative and even revolutionary ways of incorporating new elements, such as exotic scales or harmonies, into the tonal material, such as in Debussy's L'après-midi d'un faune or Scriabin's Piano Sonata No. 9 (nicknamed "The Black Mass"), or of expanding dissonant events and denying their expected resolution in such a way as to create prolonged periods of extreme harmonic tension, such as in the Prelude to Tristan und Isolde by Richard Wagner. Each of these composers, to name just a few, expanded the tonal resources available to composers in a remarkable way. Yet these expanded resources remained bound, if loosely, to the tonal organizing system, and the constraints governing the concept of consonance and dissonance remained guiding principles within which composers worked. Strained though it was, tonality was not replaced as an organizing system by these radical musical works.

The most significant and revolutionary attempt to replace the organizing system of tonality with a new one came from the composer Arnold Schoenberg. In 1908, Schoenberg eliminated the distinction between consonance and dissonance altogether and treated all twelve notes in the octave as equal. Schoenberg's new atonal music promised new sounds and textures that had never been used before in the European tradition, which would give composers an almost limitless palette of expressive resources, as is evident in one of his most famous works from this period, Pierrot Lunaire. Yet Schoenberg encountered the difficulty of organizing these sounds without the constraints of tonality. He was overwhelmed by the paradox of choice that comes with unbounded possibility. As he wrote in his essay "Composition with Twelve Tones" (1975):

Harmonic variation could be executed intelligently and logically only with due consideration of the fundamental meaning of the harmonies. Fulfillment of all these functions-comparable to the effect of punctuation in the construction of sentences, of subdivision into paragraphs, and of fusion into chapters-could scarcely be assured with chords whose constructive values had not as yet been explored.
Hence, it seemed at first impossible to compose pieces of complicated organization or of great length.

Contrary to expectations, removing the constraints of tonality did not encourage creativity but effectively hindered it.

This is an excellent demonstration of the fundamental premise of much critical work in the field of creativity, which tells us that constraints are both restrictive and generative, since they limit the number of available options to allow creators to follow established and ready-made paths to create coherent artistic works on a large scale. In the early 1920s, Schoenberg realized that to make atonality a viable compositional method, he needed to constrain the choices he could make with the material in such a way as to allow him to organize it effectively. He, therefore, devised a method that became known as serialism, in which each of the twelve tones in the octave is arranged in a row and then subject to various applied manipulations like playing it backwards (retrograde), upside-down (inversion), upside-down and backwards (retrograde inversion), etc. Serialism provided Schoenberg with the constraints that allowed him to gather his musical resources into larger units that could then be incorporated into larger and more traditional formal musical structures.

An IA perspective provides some insights into the significance of this series of shifts, as well as a demonstration of how musical innovation is often based on the manipulation of the ways in which design resources are organized. Music is sound organized according to certain parameters, notably pitch (the auditory sensation of pitches being "high" or "low"), time (how long pitches last and their arrangement into rhythmic groupings), timbre (the specific tone qualities of the sound), dynamics (how loud or quiet a note is), and form. Within these parameters, composers apply constraints or organizing principles to materials at the level of each parameter to create the foundation for a piece of music. For example, the sub-levels of pitch are domain-specific constraints such as melody, harmony, and counterpoint, while under time the sub-levels are rhythm, tempo, pulse, etc. Conventional choices for these parameter values define the familiar categories according to which musical sound is organized. Composers between the seventeenth and early twentieth centuries generally adhered to the tonal organizing system. In other words, Bach, Beethoven, Mozart and many others all created very different music, but still operated within a tightly constrained, shared set of parameter values that governed what constituted music in the eighteenth and nineteenth centuries. These properties are, of course, not only conventional, but arbitrary. Should we decide to do so, we could imagine others. We could, for example, distinguish musical sounds made by men from those made by women, or those made by 
G. Freeman and R. J. Glushko. Organization, not Inspiration: A Historical Perspective of Musical Information Architecture

\begin{tabular}{|l|l|l|}
\hline $\begin{array}{l}\text { Musical } \\
\text { Resource }\end{array}$ & Bound Approach & Agnostic Approach \\
\hline Pitch & Melody & Serial applications \\
\cline { 2 - 3 } & Harmony & \\
\cline { 2 - 3 } & Counterpoint & \\
\hline \multirow{2}{*}{ Time } & Rhythm & Rhythm \\
\cline { 2 - 3 } & Tempo & Tempo \\
\cline { 2 - 3 } & Pulse & Pulse \\
\hline Timbre & Instrumentation & Instrumentation \\
\hline Volume & $\begin{array}{l}\text { Perceived loudness } \\
\text { or quietness of } \\
\text { Form }\end{array}$ & $\begin{array}{l}\text { Perceived loudness or } \\
\text { quietness of sound }\end{array}$ \\
\hline & $\begin{array}{l}\text { The structure of a } \\
\text { piece of music } \\
\text { based on repeti- } \\
\text { tion or develop- } \\
\text { ment of musical } \\
\text { material }\end{array}$ & $\begin{array}{l}\text { The structure of a piece } \\
\text { of music based on repe- } \\
\text { tition or development } \\
\text { of musical material }\end{array}$ \\
\hline
\end{tabular}

Table 1. Bound and agnostic constraints.

people named Ludwig from those made by people named Johann. For the most part, we do not do that, but only because those distinctions do not serve any practical purpose; that could change at any time to match whatever our priorities might happen to be. The conventional category of constraints is what we have classified as bound constraints in Table 1, meaning that composers operate within them and are bound to the communal determination of how they are organized. Schoenberg's innovation was to recognize that these constraints are arbitrary, and that the constraints can be broken at will to produce new ones. Schoenberg's realization demonstrates that composers can take an agnostic perspective that ignores the bound constraints, freeing them to arrange the musical resources any way they want.

This presentation of the "bound" and "agnostic" constraints throws into stark relief the very interesting fact that Schoenberg's innovation, as radical as it appears to be, is arguably less radical than one might imagine, for of the five parameters provided here, his serial method only applies to that of pitch. French composer Pierre Boulez, in a not-so-hagiographic article after Schoenberg's death entitled "Schoenberg is Dead," (1968) criticized Schoenberg for failing to apply the serial method to the other musical parameters of duration, timbre, and dynamics. In particular, Boulez castigated Schoenberg's continued reliance on traditional classical formal structures such as sonata form, which were strongly associated with tonality, to structure and organize his post-tonal serial music. Boulez's condemnation of this regressive approach was sharp, as he asserted that the classical forms (272) "annihilate the possibilities of organization inherent in the new language" and create "maximum incoherence-a paroxysm in the absurdity of Schoenberg's incompatibilities" (273).

The basic premise of Boulez's criticism is that Schoenberg did not go far enough in breaking the constraints of the bound category in favour of agnostic constraints. In- stead of exploiting new musical possibilities, Schoenberg was simply placing his new material in an old container, tainting his supposedly radical innovation with a regressive conservatism. And while Boulez writes using the idiom of music and art, we can draw some lessons from his criticisms by applying Glushko's organizing system that sits at the heart of the IA perspective.

Selecting resource properties is the stage during which the composer decides what properties of resources are most important for their intended organization and use. For example, when we want to select a book that would be appropriate for a university course, its most important properties are "aboutness," author, publication date, and other properties useful in assessing relevance. However, if we are in the business of warehousing and shipping books, it is more important to know a book's size and weight. The selection stage is crucial, because one includes some properties while excluding others. This is precisely Boulez's criticism of Schoenberg: of the five potential properties of music that Schoenberg could have selected for applying the serial method (pitch, time, timbre, dynamics, and form), Schoenberg limited his selection only to pitch and excluded the remaining four.

During the organizing stage, the selected resource properties and the range of values they might take define an organizing principle. In Schoenberg's case, this stage is the creation of the serial method to act as a constraint on the pitch choices of a composition.

Designing the interactions with the organized resources is the stage at which Schoenberg specifies the possible ways to create a piece of music, and it is here that Boulez identified what he saw as Schoenberg's greatest error. Boulez accused Schoenberg of failing to recognize the possibilities inherent in the revolutionary organization of the pitch materials, and of simply pasting these new resources into the design patterns and formal structures derived from tonal music, which created hybrid works that fulfilled the potential of neither the old or the new idioms. The maintenance and expansion of Schoenberg's serial method infused Boulez's own music, as well as that of later generations of composers, which would embrace the idea of applying the serial method to all musical parameters to create what is sometimes referred to as total serialism.

Boulez's powerful attack on Schoenberg's approach to musical architecture provides us with a clear example of how the IA perspective can illuminate musical thought, as well as a way to use that perspective to talk about musical innovations in different musical practices at other historical periods. Figure 1 shows a summary of this brief historical example. 
G. Freeman and R. J. Glushko. Organization, not Inspiration: A Historical Perspective of Musical Information Architecture

The tonal system has been the dominant organizing system in WAM since the early eighteenth-century. It governs the musical resources relating to pitch and prescribes systematic treatments of dissonance, harmonic relationships, and chord progressions. While the tonal constraints of the early eighteenth-century were very different from those of the late nineteenth-century, the fundamental principles of tonality remain largely intact even today.

Schoenberg began by loosening the constraints of tonality, but quickly discovered that an organizing system with no constraints at all is not conducive to creativity. $\mathrm{He}$, therefore, created a rigorous organizing system he called serialism, in which all available notes within the octave are arranged into patterns and then subject to various manipulations. Schoenberg's serialism became another popular organizing system for composers in the twentieth-century, as well as a point of origin for later composers to expand and adapt it.

A summary of this organizing system according to Glushko's structure for IA is as follows:

\begin{tabular}{|l|l|}
\hline Selecting & Schoenberg selects pitch as the primary musical resource to organize. \\
\hline Organizing & Schoenberg replaces tonal constraints with serial constraints. \\
\hline Designing & $\begin{array}{l}\text { Schoenberg uses the serial method to produce pieces for consumption and study, publishes writings explaining the } \\
\text { method, and teaches the method to other composers. }\end{array}$ \\
\hline Maintaining & $\begin{array}{l}\text { Schoenberg adopts serialism as his primary method of composition, while other composers modify the approach to } \\
\text { encompass additional resources. }\end{array}$ \\
\hline
\end{tabular}

Figure 1. Summary of the Information Architecture of Serialism.

\subsection{Sensemaking and tonality as IA}

Sensemaking is the way in which humans organize resources in an attempt to impose meaning on the world in which they live. According to Glushko, we record, analyze, organize and reorganize resources and observations about those resources, both natural and artificial, as a way of navigating our way through the world and making sense of the resources it contains. Humans are quite good at sensemaking, and we are biologically hard-wired with this capacity to understand our environment by simplifying and categorizing our sensory inputs to avoid threats. More important than our biological sensemaking, however, is our intentional sensemaking, in which we organize the information in our environment and encode that information into architectures or knowledge structures that allow us both to impose meaning on those structures and facilitate our interaction with them. Weick et al. write $(2005,410)$ that the basis of sensemaking is organizing to "make sense of equivocal inputs and enact this sense back into the world to make that world more orderly."

When we consider our definition of music as an organizing system of constrained sound materials, we see that music is an ancient and ongoing process of continuous sensemaking. Consequently, musicians are extraordinary sensemakers, as musical resources are constantly being organized, reorganized, and applied to suit various aesthetic preferences across time and geography. We will demonstrate this perspective of music with a by necessity very general description of a single development in the story of the tonal system in western art music in the seventeenth and eighteenth centuries. Tonality is the organizing system against which Schoenberg and Boulez reacted, so in a way this anecdote will act as a sort of prequel to the story told above.
In WAM, the lowest voice in the musical texture is the bass. The bass provides the fundamental foundation of the musical texture, as well as the names of the chords that are built on it. In the seventeenth century, the bass was considered so fundamental that musicians developed a system of musical notation in which only the bass voice was notated on a musical staff, while the remaining voices were sketched above the bass note using numbers. These numbers indicated the intervals or steps above the bass the musician needed to fill in with the upper voices. This practice, as well as the shorthand notation, was known as thoroughbass, and it reflected the primacy of the bass voice and the constraints it imposed on the remaining voices above.

In thoroughbass, each instance of a bass with a figuration above it was generally considered an independent entity. For example, a simultaneity consisting of the notes (ascending from the bass) C-E-G would be written as a $\mathrm{C}$ in notation and then the numbers $5 / 3$ above, while a simultaneity consisting of the notes (again ascending from the bass) E-G-C would be written with an $\mathrm{E}$ in notation with the numbers $6 / 3$ above (the numbers represent musical intervals, which can be calculated simply by counting letter names in accordance with the musical alphabet, which runs from A-G and then starts over again). C5/3 and E6/3 were considered separate entities, despite the fact that they consist of the same set of notes in different arrangements.

Thoroughbass is, therefore, an effective method for notating harmony for performers. Yet it is considerably more than that, for what appears to be a simple notational method for performance practice actually contains a complex and tacit framework of musical relationships, and it was incumbent on the performer to have a thorough understanding of these relationships in order to navigate thoroughbass in the correct way (Holtmeier 2007). Johann Friedrich Daube, in 
1756, describing the qualifications required for performing thoroughbass, wrote (quoted in Holtmeier 2007, 8):

Without a complete understanding of harmony it is impossible to play thoroughbass correctly." According to Daube, this understanding includes: “(1) from whence most chords originate, (2) to where they may be connected, and (3) how, from the first chord, one can deduce subsequent ones.

The architecture of knowledge the musician had to possess, and upon which their ability to understand thoroughbass relied, was, therefore, implicitly and tacitly understood to be already present. As Keiler has written $(2013,288)$, “it is clear enough what is meant, in a given treatise, but the limits or extent of the knowledge out of which practical rules are formulated-the mental origin of their practical formulation-is much harder to determine." What thoroughbass practice, therefore, lacked, despite its rich tapestry of musical and compositional resources, was a rigorous and systematic approach to its theory and pedagogy. Since each simultaneity was considered a separate entity, there could be no single principle to systematize and govern the nearly infinite number of possible relationships between them in a way that could be effectively abstracted and theorized (Lester 2002). While the compositional possibilities in this approach were extensive, the pedagogy was complex, and instructional materials that attempted to summarize the thoroughbass approach for teaching were often catalogue-like treatises that dealt with classifying these simultaneities and governing their movement from one to the next. As just one example of these treatises, Der General-Bass in der Composition by Johann David Heinichen from 1728 is a treatise that lays out the author's prescriptions for thoroughbass and weighs in at an impressive 960 pages.

In 1722, Jean-Philippe Rameau proposed a rigid logic for identifying harmonic simultaneities and imposing a systematic governance on their progression from one to the next. He did this by categorizing the vast array of independent simultaneities according to their similarities and common features. To use our example from above, Rameau considered the two simultaneities (ascending from the bass: C-E-
G and E-G-C) to be two different figurations of the same harmonic entity. Since C-E-G consists entirely of thirds (C$\mathrm{E}$ is a distance of a third and E-G is a distance of a third), and the third is considered a consonant interval, this arrangement of the notes was considered the "root" position, suggesting that it is the most stable and consonant arrangement of these notes, with the arrangement E-G-C being a variation of this entity. The note $\mathrm{C}$ is therefore the most important note in this set, as it is the note that gives the simultaneity its name and dictates its function, since we would now consider both C-E-G and E-G-C to be different figurations of "C" simultaneities." "C $\mathrm{C}$ " is what Rameau referred to as the fundamental bass, which means that it is the most important note in each of the sets even if it does not sit in the actual bass voice. The concept of the fundamental bass constituted a principle that allowed Rameau to categorize the many separate harmonic simultaneities and assign them common identities based on their similarities. With a smaller number of categories of harmonic simultaneities, which we can now refer to as chords, Rameau was then able to analyze the way in which the entities within each larger category of chord behaved, draw general conclusions about their typical behavior, quantify that behavior by making explicit their general patterns, and subordinate those movements to a larger principle that governed them. This larger principle became the prescriptive grammar that constrained the behavior of chords to repeatable and coherent patterns, thereby creating the organizing system we today refer to as tonality, in which the relationships between consonance and dissonance are more rigidly subordinated to a prescriptive and iterative system. Figure 2 provides a summary of this brief historical example.

Weick, Sutcliffe and Obstfield (2005) provide a model of the principles of sensemaking, some parts of which we will repurpose here to show how Rameau's project represents an excellent example of how musical thought is a constant creation and revision of a musical information architecture.

\subsection{Sensemaking organizes flux}

Sensemaking begins with an undifferentiated stream of events that contains the potential for a seemingly infinite

In the seventeenth-century, music for accompanying singers or other instrumentalists on the keyboard or lute was frequently written in a shorthand notation known as figured bass, in which a bass note appeared on the staff with numbers included to indicate the intervals of the notes that should be played above it. Thoroughbass, though perhaps having the appearance of being a simple notational convention, was an extremely complex practice that relied extensively on implicit understanding and tacit knowledge of musical conventions and logic, yet lacked iterative fundamental principles for organizing and communicating this understanding clearly and effectively.

Rameau created a simpler and more accessible information architecture by imposing a unified theory of organization upon the complex practices of thoroughbass. Rameau's concept of tonality subordinated disparate harmonic entities to fundamental principles of organization to make their relationships more explicit, observable, and iterative, thereby fundamentally altering the way in which subsequent generations of musicians perceived musical harmony.

Figure 2. Summary of the Information Architecture of Rameau. 
cluster of potential actions, misdirection, mistakes, and successes. In the thoroughbass period, this stage is the potential information overload of the thoroughbass performance practice and treatises.

\subsection{Sensemaking starts with noticing and bracketing}

Events, actions and processes can be ongoing, but they have not necessarily been recognized as significant or part of a larger rule that would provide them some contextual logic. Rameau observed that frequently occurring patterns and tendencies towards certain idioms in thoroughbass suggested a tacit recognition of their adherence to a larger fundamental principle that had, at that point, remained unexplored and unarticulated.

\subsection{Sensemaking is about labeling}

Labeling is a way of suggesting plausible methods of managing information and executing actions based on that information. Labels gather up granular analysis of individual events and create larger and more frequently occurring patterns that can be memorized and recalled more easily. Labeling of musical resources was ubiquitous for the thoroughbass practitioners, and many of the thoroughbass treatises, such as the Heinichen mentioned above, consisted of heuristics for memorizing thoroughbass patterns and realizing them in performance. Rameau would expand this exercise in labeling by recognizing the implicit categories of the musical resources composers were already using.

\subsection{Sensemaking is retrospective and social}

Sensemaking uses data derived from experience to trace developments and interactions over time. Rameau derived his harmonic theory by applying deductive reasoning to existing practices, practices that had themselves been derived from earlier musical practices. As Lester observes (2002), many of the elements Rameau organized were recognized as significant by many other theorists across Europe even before Rameau was born, but they lacked a single deductive perspective to rein them into a unified system.

\subsection{Sensemaking is about organizing through communication}

Communication is how sensemaking becomes information architecture. By gathering unstructured information into an organizing system and publishing that organizing system in the Traité de l'harmonie in 1722, Rameau effectively communicated his sensemaking activity to others to facilitate their use of musical resources, fundamentally revolutionizing compositional pedagogy in the process.
By observing existing musical practices, applying deductive reasoning, and creating an organizing system that governed the application of musical resources, Rameau effectively engaged in sensemaking to create an information architecture and then facilitated wayfinding through that architecture by means of his theoretical pedagogy. As Lester writes (2002), Rameau's sensemaking exercise was one of the most important revolutions in western musical thought, for it organized a vast array of disparate performance practices under a unifying principle derived from deductive reasoning. The impact of the fundamental bass approach to music analysis and composition has also had an enormous impact on everything from the pedagogical approach to WAM since the nineteenth-century to that of jazz and popular music today.

Despite the theoretical revolution Rameau instigated, it is important to avoid the value judgement that would suggest that his tonal system is better than thoroughbass simply by virtue of having applied to it a systematic information architecture. Indeed, one could make the legitimate argument that Rameau's project actually served to conceal and even eradicate a rich musical tradition by encouraging the perspective of thoroughbass as antiquated. As Lambe has written (2007), taxonomies, of which we must surely consider Rameau's system to be an example, not only reveal information and make it visible, they also conceal and destroy by exclusion. For much of the twentieth-century, thoroughbass was an unjustly neglected field of musical pedagogy, and it is only within the last few decades that the field of historically informed music theory has sought to rectify this by reconstituting the contextual implications of thoroughbass to reveal the insights into the historical repertoire that Rameau's approach had obscured (Holtmeier 2007).

\subsection{Conclusion}

For Stravinsky, it was organization, not simply inspiration, that produced the catalyst for writing music, as when he wrote the following $(1998,51)$ : "This appetite that is aroused in me at the mere thought of putting in order musical elements that have attracted my attention is not at all a fortuitous thing like inspiration, but as habitual and periodic, if not as constant, as a natural need."

The impetus to composition was, therefore, the desire to organize musical materials in ways that caught his attention and were pleasing to him, in much the same way as composers in other musical practices seek to apply organizational methods that fulfill the expectations of specific styles and genres. In this paper, we have looked at musical inspiration as the fundamental principle of sound organized according to constraints so that we can examine more clearly and without recourse to advanced music the- 
ory how musicians make sense of their information environments. It is, therefore, our hope that this preliminary examination will inspire further work that will explore the application of the principles of information architecture to other musical genres and practices.

\section{References}

Abrahamsen, Knut Tore. 2003. "Indexing of Musical Genres: An Epistemological Perspective.” Knowledge Organization 30: 144-69.

Adcock, Lucy. 2001. "Building a Virtual Music Library: Towards a Convergence of Classification within Internetbased Catalogues." Knowledge Organization 28: 66-74.

Arango, Jorge. 2011. "Architectures." Journal of Information Architecture 3, no. 1. http://journalofia.org/volume3/ issue1/04-arango/

Bawden, David and Lyn Robinson. 2009. "The Dark Side of Information: Overload, Anxiety, and Other Paradoxes and Pathologies." Journal of Information Science 35, no. 2: 180-91. doi:10.1177/0165551508095781

Boulez, Pierre. 1968. "Schoenberg is Dead." In Notes of an Apprenticeship, texts collected and presented by Paule Thévenin, trans. Herbert Weinstock. New York, A.A. Knopf, 268-76.

Fishman, Joseph P. 2015. "Creating Around Copyright." Harvard Law Review 128: 334-404.

Glushko, Robert J., ed. 2016. The Discipline of Organizing, $4^{\text {th }}$ ed. Sebastopol: O'Reilly Media.

Holtmeier, Ludwig. 2007. "Heinichen, Rameau, and the Italian Thoroughbass Tradition: Concepts of Tonality and Chord in the Rule of the Octave." Journal of Music Theory 51, no. 1: 5-49.

Keiler, Allan. 2013. "The Problem of the Retrieval of Musical Knowledge: The Thoroughbass Tradition and Its Relationship to Rameau." Journal of Music Theory 57, no. 2: 287-320. doi:10.1215/00222909-2323488

Lambe, Patrick. 2007. Organising Knowledge: Taxonomies, Knowledge and Organisational Effectiveness. Chandos Knowledge Management Series. Oxford: Chandos.

Lee, Deborah Theresa Lee. 2017a. "Modelling Music: A Theoretical Approach to the Classification of Notated Western Art Music.” PhD diss., City, University of London. http://openaccess.city.ac.uk/17445/1/Lee $\% 2 C \%$ 20Deborah.pdf

Lee, Deborah. 2017b. "Numbers, Instruments and Hands: The Impact of Faceted Analytical Theory on Classifying Music Ensembles.” Knowledge Organization 44: 405-15.

Lee, Deborah, Lyn Robinson, and David Bawden. 2019. "Modeling the Relationship Between Scientific and Bibliographic Classification for Music." Journal of the Association for Information Science and Technology 70: 230-41. doi:10.1002/asi.24120
Lester, Joel. 1992. Compositional Theory in the Eighteenth Century. Cambridge, MA: Harvard University Press.

Lester, Joel. 2002. "Rameau and Eighteenth-Century Harmonic Theory." In Cambridge History of Music Theory, ed. Thomas Christensen. Cambridge: Cambridge University Press, 753-57. doi:10.1017/CHOL9780521623711. 026

Pearce, Marcus and Martin Rohrmeier. 2012. "Music Cognition and Cognitive Sciences." Topics in Cognitive Science 4: 468-84. doi:10.1111/j.1756-8765.2012.01226.x

Salimpoor, Valorie N., David H. Hald, Robert J. Zatorre, Alain Dagher, and Anthony Randal McIntosh. "Predictions and the Brain: How Musical Sounds Become Rewarding." Trends in Cognitive Science 19, no. 2: 86-87.

Schoenberg, Arnold. 1975. Style and Idea: Selected Writings of Arnold Schoenberg, ed. Leonard Stein, trans. Leo Black. London: Faber.

Schwartz, Barry. 2004. The Paradox of Choice: Why More is Less. New York: HarperCollins.

Smiraglia, Richard P. 2002. "Musical Works and Information Retrieval." Notes: The Quarterly Journal of the Music Library Association 58: 747-64.

Smiraglia, Richard P. 2017. Describing Music Materials: A Manual for Resource Description of Printed and Recorded Music and Music Videos. $4^{\text {th }}$ ed. Lanham, MD: Rowman \& Littlefield.

Smiraglia, Richard P. and Ann M. Graf. 2017. "From Music Cataloging to the Organization of Knowledge: An Interview with Richard P. Smiraglia." Cataloging \& Classification Quarterly 55, no. 5: 269-88. doi:10.1080/01639374.2017. 1312653

Stokes, Patricia D. 2013. "Crossing Disciplines: A Constraint-Based Model of the Creative/Innovative Process." Journal of Productivity and Innovative Management 31, no. 2: 247-58. doi: 10.1111/jpim.12093

Stravinsky, Igor. 1998. Poetics of Music in the Form of Six Lessons, trans. Arthur Knodel and Ingolf Dahl. Cambridge, MA: Harvard University Press.

Thomas, David H. and Richard P. Smiraglia. 1998. "Beyond the Score:" Notes: The Quarterly Journal of the Music Library Association 54: 649-66.

Weick, Karl E., Kathleen M. Sutcliffe, and David Obstfeld. 2005. "Organizing and the Process of Sensemaking." Organization Science 16: 409-21. doi:10.1287/orsc.1050. 0133

Weissenberger, Lynnsey K. 2015. "Traditional Musics and Ethical Considerations of Knowledge and Documentation Processes." Knowledge Organization 42: 290-5.

Wu, Dan and Jinsong Shi. 2016. "Classical Music Recording Ontology Used in a Library Catalog.” Knowledge Organization 43: 416-30. 